\title{
Structural, Optical, and Luminescence Properties of Reactive Magnetron Sputtered Tungsten Oxide Thin Films
}

\author{
V. Madhavi, P. Kondaiah, O. M. Hussain, and S. Uthanna \\ Department of Physics, Sri Venkateswara University, Tirupati 517 502, India \\ Correspondence should be addressed to V. Madhavi, madhuvphysics@gmail.com
}

Received 30 September 2012; Accepted 5 November 2012

Academic Editors: E. Lidorikis, V. Matejec, and X. Shu

Copyright () 2012 V. Madhavi et al. This is an open access article distributed under the Creative Commons Attribution License, which permits unrestricted use, distribution, and reproduction in any medium, provided the original work is properly cited.

Tungsten oxide $\left(\mathrm{WO}_{3}\right)$ thin films were deposited on to unheated Corning glass and silicon substrates by RF magnetron sputtering of metallic tungsten target at various oxygen partial pressures in the range $4 \times 10^{-2}-1 \times 10^{-1} \mathrm{~Pa}$. The influence of oxygen partial pressure on the structure and surface morphology and the optical and photoluminescence properties of the films were investigated. $\mathrm{X}$-ray diffraction studies revealed that the deposited films were amorphous in nature. Fourier transform infrared transmission spectra confirmed that the presence of stretching vibration of W-O-W and deformation of $\mathrm{W}-\mathrm{O}$ bonds related to the $\mathrm{WO}_{3}$. The optical transmittance of the films at wavelengths $>500 \mathrm{~nm}$ increased from $62 \%$ to $85 \%$ with the increase of oxygen partial pressure. The optical band gap of the films increased from 3.00 to $3.14 \mathrm{eV}$ and the refractive index of the films decreased from 2.26 to 2.08 with the increase of oxygen partial pressure from $4 \times 10^{-2}$ to $1 \times 10^{-1} \mathrm{~Pa}$, respectively. The photoluminescence studies indicated that the intense blue emission which was assigned to band-to-band transition was observed at oxygen partial pressure of $6 \times 10^{-2} \mathrm{~Pa}$.

\section{Introduction}

Transition metal oxide thin films have attractive technological importance for electrochromic devices. Among the transition metal oxides, tungsten oxide $\left(\mathrm{WO}_{3}\right)$ is an $\mathrm{n}$ type semiconductor, exhibits electrochromic properties in the visible and infrared regions, is relatively low cost, and has high color efficiency [1]. It possesses excellent coloration efficiency and electrochemical stability after insertion with protons or other small monovalent cations such as $\mathrm{Li}^{+}$and $\mathrm{Ni}^{+}$[2]. Hussain et al. [3] reported on pulsed laser deposited $\mathrm{WO}_{3}$ films, formed at substrate temperature $573 \mathrm{~K}$, that the crystallinity of the triclinic $\mathrm{WO}_{3}$ decreased with the increase of oxygen partial pressure from 10 to $26 \mathrm{~Pa}$, and at higher oxygen partial pressure of $40 \mathrm{~Pa}$ the films were almost in amorphous structure. Kaushal and Kaur [4] achieved nanocrystalline $\mathrm{WO}_{3}$ films by pulsed DC magnetron sputtering at substrate temperature of $873 \mathrm{~K}$ with the optical band gap of $3.39 \mathrm{eV}$ and the crystallite size, and optical band gap of the films increased with the increase of oxygen partial pressure. Bittencourt et al. $[5,6]$ reported on the $\mathrm{WO}_{3}$ thin films formed by RF magnetron sputtering at different argon: oxygen ratios on the structural and composition of the films and achieved the stoichiometric films at 1:1 of argon and oxygen ratio. Subramanyam and Karuppasamy [7] formed the $\mathrm{WO}_{3}$ films at room temperature by pulsed $\mathrm{DC}$ magnetron sputtering in active arc suspension mode at different oxygen partial pressures in the range 1.5-5.2 Pa. The films formed at high oxygen partial pressure of 5.2 Pa exhibited the refractive index of 2.1 and optical band gap of $3.12 \mathrm{eV}$ and the refractive index decreased with the increase of oxygen partial pressure.

Different deposition methods have been used to prepare $\mathrm{WO}_{3}$ films such as the chemical and physical deposition processes like electrospinning [8], spray pyrolysis [9], electrodeposition [10], thermal evaporation [11], plasma assisted evaporation [12], and DC and RF magnetron sputtering techniques $[6,7,13]$. Among these, magnetron sputtering has the advantage to deposit uniform films on large area substrates. The metal oxide films can be deposited from metallic target in the presence of reactive gas of oxygen in the process of reactive sputtering. In this reactive magnetron sputtering technique, magnetron cathode has the advantage in the growth of uniform films at low applied voltages compared to diode sputtering. 
TABLE 1: Deposition conditions for preparation of $\mathrm{WO}_{3}$ films.

\begin{tabular}{lc}
\hline Sputter target & Tungsten $(50 \mathrm{~mm}$ dia. $)$ \\
Target to substrate distance & $50 \mathrm{~mm}$ \\
Base pressure & $4 \times 10^{-4} \mathrm{~Pa}$ \\
Oxygen partial pressure $\left(\mathrm{pO}_{2}\right)$ & $4 \times 10^{-2}-1 \times 10^{-1} \mathrm{~Pa}$ \\
Sputter pressure & $4 \mathrm{~Pa}$ \\
Sputter power & $150 \mathrm{~W}$ \\
Substrate temperature & $303 \mathrm{~K}$ \\
\hline
\end{tabular}

The physical properties of the magnetron sputtered films mainly depend on the deposition parameters such as oxygen partial pressure, substrate temperature, and sputter power. In the present investigation, thin films of $\mathrm{WO}_{3}$ were formed by RF magnetron sputtering of metallic tungsten target under various oxygen partial pressures. The influence of oxygen partial pressure on the compositional, structure, and surface morphology and optical and photoluminescence properties was systematically studied and the results were reported.

\section{Experimentation}

The $\mathrm{WO}_{3}$ thin films were deposited on Corning glass and $\mathrm{Si}$ substrates were maintained at room temperature by RF magnetron sputtering of (99.99\% pure) tungsten target of (50 $\mathrm{mm}$ diameter) under different oxygen partial pressures. The vacuum pumping system was employed for sputter deposition using a combination of diffusion and rotary pumps to achieve an ultimate pressure of $4 \times 10^{-4} \mathrm{~Pa}$. Pure oxygen and argon were used as reactive and sputter gases, respectively. Required quantities of oxygen and argon gases were admitted into the sputter chamber through fine controlled needle valves and their flow rates were monitored individually employing Aalborg mass flow controllers. Digital Pirani and Penning gauges were used to measure the pressure in the sputter chamber. The films were prepared on the substrates held at room temperature at different oxygen partial pressures in the ranges $4 \times 10^{-2}-1 \times 10^{-1} \mathrm{~Pa}$. The RF power fed to the sputter target was $150 \mathrm{~W}$ using Advance Energy RF power source and the deposition time was $120 \mathrm{~min}$. Deposition conditions maintained during the preparation of $\mathrm{WO}_{3}$ films are given in Table 1.

The thickness of the films deposited on Corning glass substrates was measured by using $\alpha$-step profilometer. Seifert X-ray diffraction (model 3003TT) with $\mathrm{Cu} \mathrm{K \alpha}$ radiation source $(\lambda=0.15406 \mathrm{~nm})$ was used to determine the crystallographic structure of the films. The chemical composition of the films formed on glass substrates was analyzed with energy dispersive X-ray analysis (Philips XL 308) attaching to scanning electron microscope. The chemical bonding configuration of the films formed on silicon substrates was obtained from the Fourier transform infrared spectrophotometer (Nicolet model 5700 FTIR). The surface morphology of the films was carried out by using atomic force microscope (Digital Instrument 3100 series). The optical transmittance and reflectance of the films formed on glass substrates were recorded by using UV-Vis-NIR (Perkin

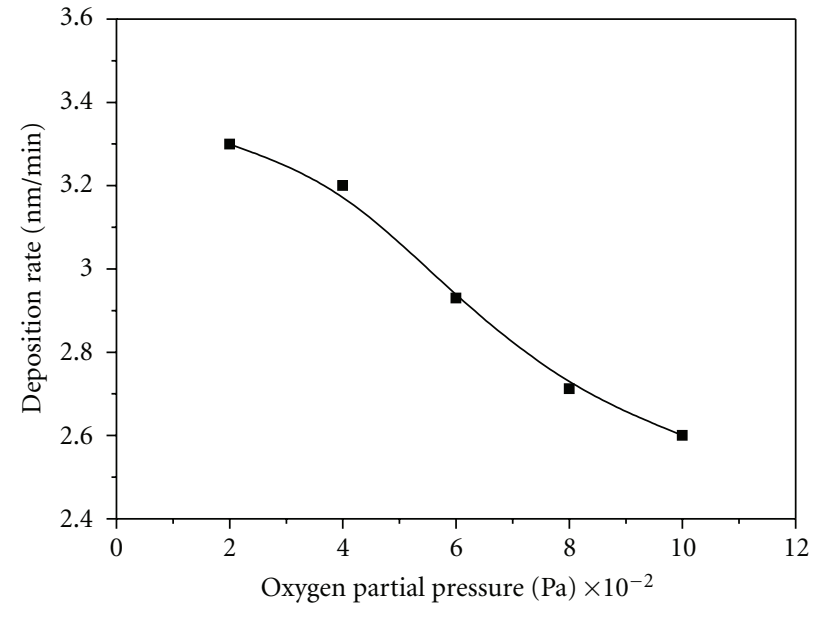

FIgURE 1: Variation of deposition rate of $\mathrm{WO}_{3}$ films with oxygen partial pressure.

Elmer model Lambda 950) double beam spectrophotometer in the wavelength range $300-1000 \mathrm{~nm}$. Photoluminescence spectra of the films were obtained using a Hitachi U-4700 spectrophotometer under excitation wavelength of $375 \mathrm{~nm}$.

\section{Results and Discussions}

In order to study the influence of oxygen partial pressure on the physical properties, tungsten oxide films were deposited under various oxygen partial pressures in the range $4 \times 10^{-2}-1 \times 10^{-1} \mathrm{~Pa}$ and maintained other deposition parameters as constant. The measured thickness of the films was in the range $313-398 \mathrm{~nm}$. The variation of deposition rate with oxygen partial pressure of the $\mathrm{WO}_{3}$ films is shown in Figure 1. It is seen that the deposition rate was decreased with the increase of oxygen partial pressure. The deposition rate of the films formed at low oxygen partial pressure of $4 \times 10^{-2} \mathrm{~Pa}$ was $3.44 \mathrm{~nm} / \mathrm{min}$ and it decreased to $2.62 \mathrm{~nm} / \mathrm{min}$ with the increase of oxygen partial pressure to $1 \times 10^{-1} \mathrm{~Pa}$. The high deposition rate at low oxygen partial pressure was due to the high sputtering yield of metallic tungsten and availability of insufficient oxygen for reaction with tungsten. Sun et al. [14] also noted the deposition rate of $4 \mathrm{~nm} / \mathrm{min}$ in pulsed DC magnetron sputtered $\mathrm{WO}_{3}$ films formed with sputter power of $100 \mathrm{~W}$. The decrease of deposition rate at higher oxygen partial pressures was due to availability of sufficient oxygen to react with the tungsten ions and also it leads to formation of oxide layer on the surface of the target which generally reduces the deposition rate [15].

3.1. Chemical Composition. The chemical composition of the films deposited on glass substrate was analyzed with energy dispersive X-ray analysis. The atomic ratio of oxygen to tungsten was at low value of 2.66 at low oxygen partial pressure of $4 \times 10^{-2} \mathrm{~Pa}$ due to the growth of tungsten along with tungsten oxide in the films. A representative EDAX spectrum of the films formed at oxygen partial pressure of 


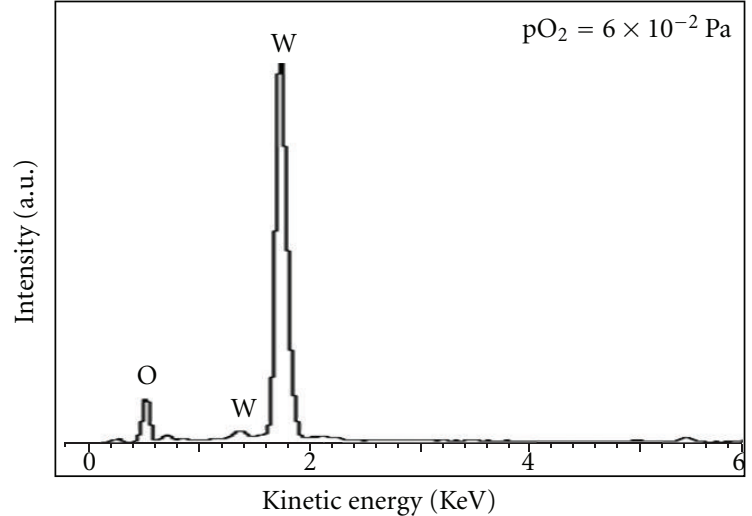

FIgURE 2: EDAX spectrum of $\mathrm{WO}_{3}$ films formed at oxygen partial pressure of $6 \times 10^{-2} \mathrm{~Pa}$.

$6 \times 10^{-2} \mathrm{~Pa}$ is shown in Figure 2. For the films formed at oxygen partial pressure of $6 \times 10^{-2} \mathrm{~Pa}$, the atomic ratio of oxygen to tungsten was 2.98 and was almost constant at higher oxygen partial pressures. It indicated that the films formed at oxygen partial pressure of $6 \times 10^{-2} \mathrm{~Pa}$ were of nearly stoichiometric $\mathrm{WO}_{3}$.

3.2. Structural Properties. Figure 3 shows the X-ray diffraction profiles of the films formed at different oxygen partial pressures. The broad diffraction pattern of the films formed at different oxygen partial pressures indicated that the films were amorphous in nature. Mohamed et al. [16] reported that amorphous $\mathrm{WO}_{3}$ films formed on unheated glass substrates at oxygen partial pressure $>5.7 \times 10^{-3} \mathrm{~Pa}$ by DC magnetron sputtering.

Fourier transform infrared spectra of $\mathrm{WO}_{3}$ films formed at different oxygen partial pressures in the wavenumber range $400-1500 \mathrm{~cm}^{-1}$ are shown in Figure 4. The films formed at low oxygen partial pressure of $4 \times 10^{-2} \mathrm{~Pa}$ showed a broad absorption band in between 600 and $1000 \mathrm{~cm}^{-1}$. The broadness of the absorption band suggested that the deposited films were amorphous in nature. When the oxygen partial pressure increased to $6 \times 10^{-2} \mathrm{~Pa}$, the broad absorption band centered at $780 \mathrm{~cm}^{-1}$ and a shoulder at about $590 \mathrm{~cm}^{-1}$ was observed. The absorption band observed at $780 \mathrm{~cm}^{-1}$ attributed to the $\mathrm{O}-\mathrm{W}-\mathrm{O}$ stretching mode of tungsten oxide [17]. The band seen at $590 \mathrm{~cm}^{-1}$ related to the deformation mode of $\mathrm{W}-\mathrm{O}$ in $\mathrm{WO}_{3}$ [18]. In addition, an absorption band seen at $1150 \mathrm{~cm}^{-1}$ was due to the presence of $\mathrm{Si}-\mathrm{O}$ band of the silicon oxide present on the silicon substrate and the peaks observed at 1338 and $1430 \mathrm{~cm}^{-1}$ were attributed to the weakly bounded water due to exposure of the films to the ambient air. The presence of such broad bands was also noticed by the Rougier et al. [19] in pulsed laser deposited $\mathrm{WO}_{3}$ films formed at different oxygen partial pressures.

3.3. Surface Morphology. Figure 5 shows three- and twodimensional atomic force microscope images of $\mathrm{WO}_{3}$ films deposited at different oxygen partial pressures. The surface of the films deposited at lower oxygen partial pressure
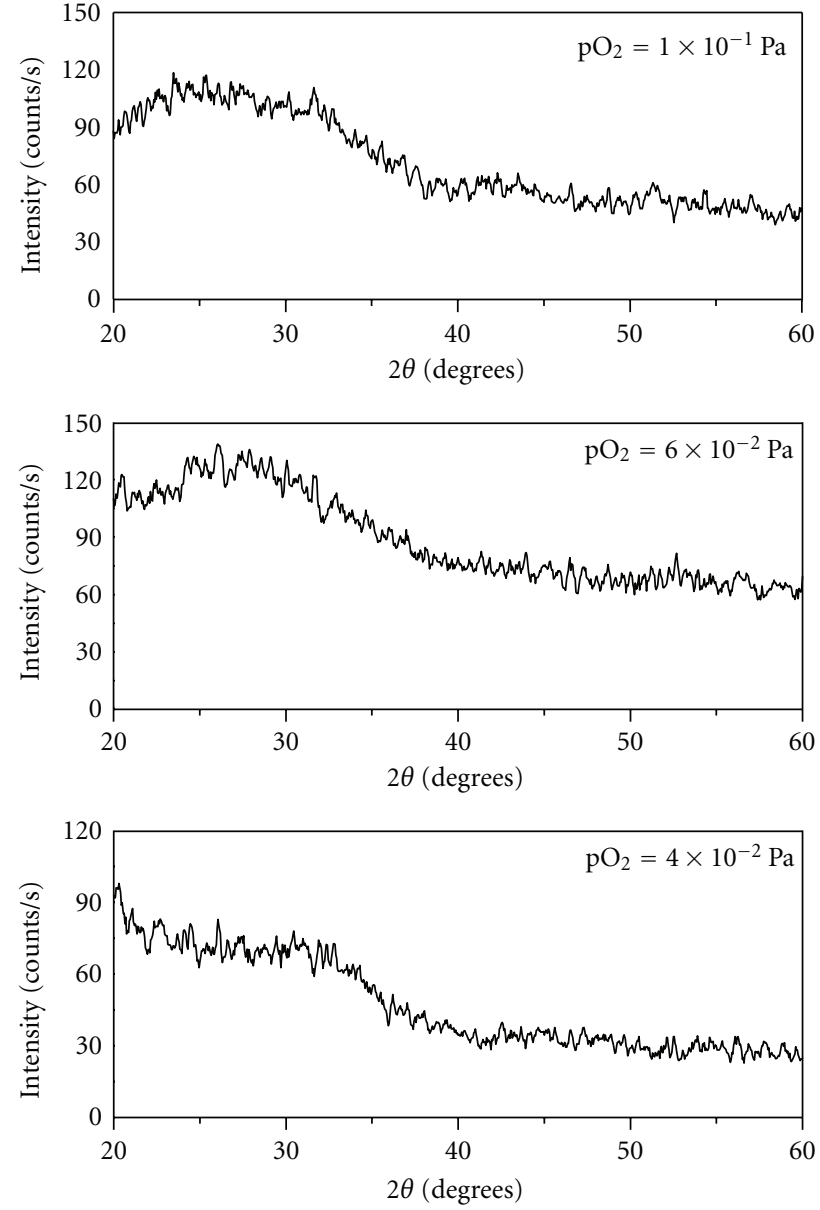

FIgure 3: XRD profiles of $\mathrm{WO}_{3}$ films formed at different oxygen partial pressures.

of $4 \times 10^{-2} \mathrm{~Pa}$ (Figure 5(a)) was smooth with small size grains and surface roughness of $2.26 \mathrm{~nm}$. The films formed at oxygen partial pressure of $6 \times 10^{-2} \mathrm{~Pa}$ (Figure 5(b)) showed the uniformly distributed grains on the surface. In a further increase of oxygen partial pressure to $1 \times 10^{-1} \mathrm{~Pa}$, the films exhibited pyramidal shape grains as shown in Figure 5(c). The average grain size of the films increased from 93 to $252 \mathrm{~nm}$ and the surface roughness of the films decreased from $2.26 \mathrm{~nm}$ to $1.57 \mathrm{~nm}$ with the increase of oxygen partial pressure from $4 \times 10^{-2}$ to $1 \times 10^{-1} \mathrm{~Pa}$, respectively. The morphological evolution of growing surface with oxygen partial pressure was greatly affected due to variation in the energy of impinging particles and the rate of impingement and the mobility of the arrived particles onto the surface of the substrates.

3.4. Optical Properties. The optical properties of the films were found to be strongly influenced by the oxygen partial pressure. The optical transmittance spectra of the $\mathrm{WO}_{3}$ films formed at different oxygen partial pressures are shown in Figure 6. The optical transmittance of the films at wavelengths $\geq 500 \mathrm{~nm}$ increased from $60 \%$ to $82 \%$ with the increase of oxygen partial pressure from $4 \times 10^{-2}$ 

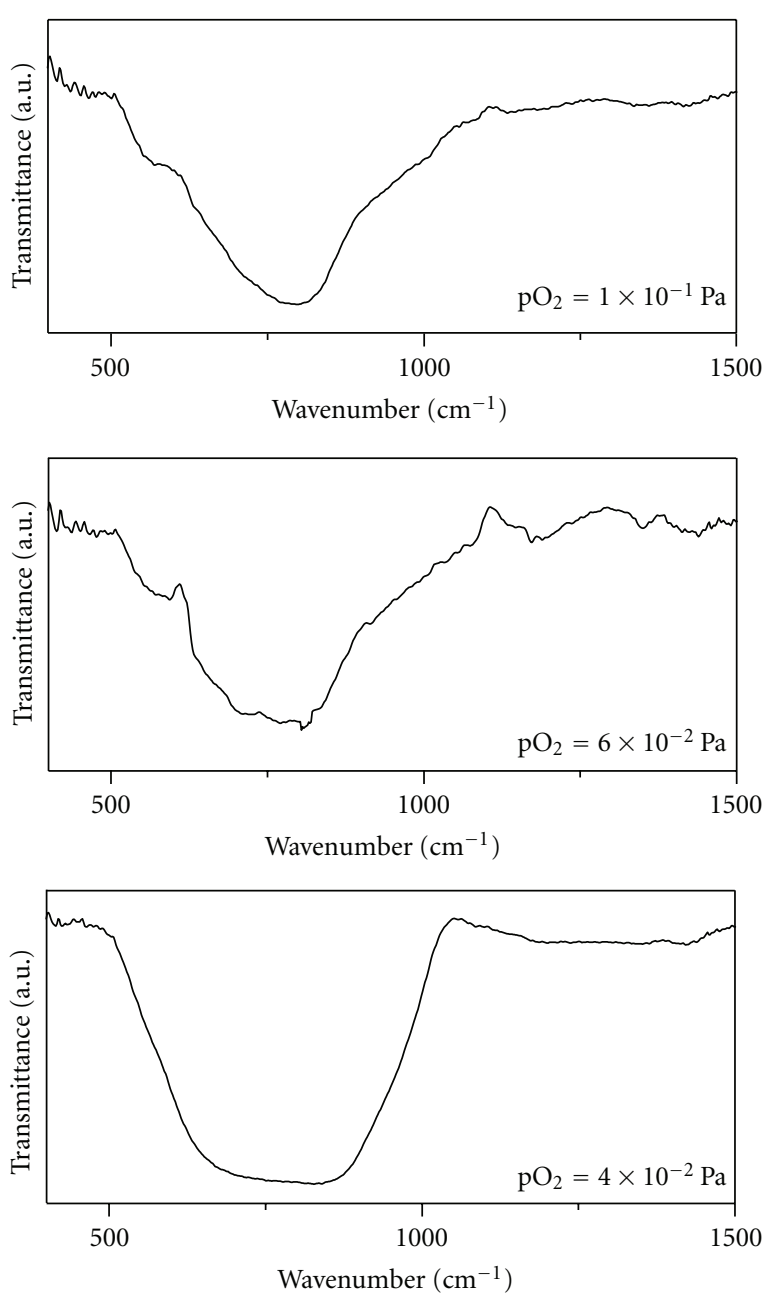

FIGURE 4: FTIR spectra of $\mathrm{WO}_{3}$ films formed at different oxygen partial pressures.

to $1 \times 10^{-1} \mathrm{~Pa}$, respectively. At lower oxygen partial pressure, high energy sputtered species were traveled through plasma and large number of tungsten ions reached at the substrate due to heavier mass of the tungsten compared to oxygen atoms. Due to this reason, the films formed at low oxygen partial pressure exhibited lower optical transmittance of $60 \%$. With the increase of oxygen partial pressure of $6 \times$ $10^{-2} \mathrm{~Pa}$ in the sputtering chamber, both the oxygen and tungsten will effectively react on the substrate surface and form nearly stoichiometric films, hence the optical transmittance increased to $70 \%$. At higher oxygen partial pressure of $1 \times 10^{-1} \mathrm{~Pa}$, the excess of oxygen atoms was reached the substrate, hence the films showed high transmittance of $82 \%$ [20]. Kaushal and Kaur [4] reported such an increase in the optical transmittance of $\mathrm{WO}_{3}$ films with the increase of oxygen partial pressure formed by pulsed laser deposition. Lethy et al. [21] also reported on the pulsed laser deposition films that the optical transmittance increased from $40 \%$ to $80 \%$ in $\mathrm{WO}_{3}$ films with the increase of oxygen partial pressures from 0.006 to 0.12 mbar which was correlated with the charge transport of the sputter species present in the sputter chamber. The sharp absorption edge was observed in the wavelength region $450-500 \mathrm{~nm}$ and the absorption edge shifted towards lower wavelengths side with the increase of oxygen partial pressure. The optical reflectance of the films formed at different oxygen partial pressures is shown in Figure 7. The optical absorption coefficient $(\alpha)$ of the films was calculated from the optical transmittance $(T)$ and reflectance $(R)$ data using the following relation:

$$
\alpha=-\left(\frac{1}{t}\right) \ln \left[\frac{T}{(1-R)^{2}}\right],
$$

where $t$ is the film thickness. The optical absorption in the films was fitted to the following relation:

$$
(\alpha h \nu)^{2}=A(h \nu-E g),
$$

assuming that the direct transitions take place from the top of the valance band and bottom of the conduction band. Figure 8 shows the plots of $(\alpha h \nu)^{2}$ versus photon energy $(h \nu)$ of the films formed at different oxygen partial pressures. The extrapolation of linear portion of the plots to $\alpha=0$ leads to the optical band gap. The optical band gap of the $\mathrm{WO}_{3}$ films increased from 3.00 to $3.14 \mathrm{eV}$ with the increase of oxygen partial pressure from $4 \times 10^{-2}$ to $1 \times 10^{-1} \mathrm{~Pa}$, respectively. The increase of optical band gap with the increase of oxygen partial pressure was due to reduction in the oxygen vacancies. The achieved optical band gap values were in good agreement with the DC magnetron sputtering tungsten oxide films, where the optical band gap increased from 2.97 to $3.14 \mathrm{eV}$ with the increase of oxygen partial pressure from 1.5 to $5.2 \mathrm{~Pa}$ [7]. Chawla et al. [22] reported that the optical band gap of the RF sputtered films increased from 2.76 to $3.07 \mathrm{eV}$ with increase of oxygen content from $10 \%$ to $40 \%$ in sputter chamber by RF magnetron sputtering. Mohamed et al. [16] reported that the optical band gap of the films increased from 2.90 to $3.18 \mathrm{eV}$ with the increase of oxygen partial from 0.20 to $0.52 \mathrm{~Pa}$. The increased of optical band gap with oxygen partial pressure can be explained due to the decrease in the defect centers by improving the stoichiometry of the films. The difference in the optical band gap values was due to process parameters maintained for the growth of the films which were different for different deposition methods.

The refractive index $(n)$ of the films was determined from the optical transmittance interference data employing Swanepoel's envelope method [23] using the following relation:

$$
\begin{gathered}
n(\lambda)=\left[N+\left(N^{2}-n_{0}^{2} n_{1}^{2}\right)^{1 / 2}\right]^{1 / 2}, \\
N=2 n_{0} n_{1}\left[\frac{T_{\max }-T_{\min }}{T_{\max } T_{\min }}\right]+\frac{\left(n_{0}^{2}+n_{1}^{2}\right)}{2},
\end{gathered}
$$

where $n_{o}$ and $n_{1}$ are the refractive indices of air and substrate and $T_{\max }$ and $T_{\min }$ are the optical transmittance maximum and minimum, respectively.

Figure 9 shows the wavelength dependence of refractive index of $\mathrm{WO}_{3}$ films formed at different oxygen partial pressures. For all the films, the refractive index was decreased 

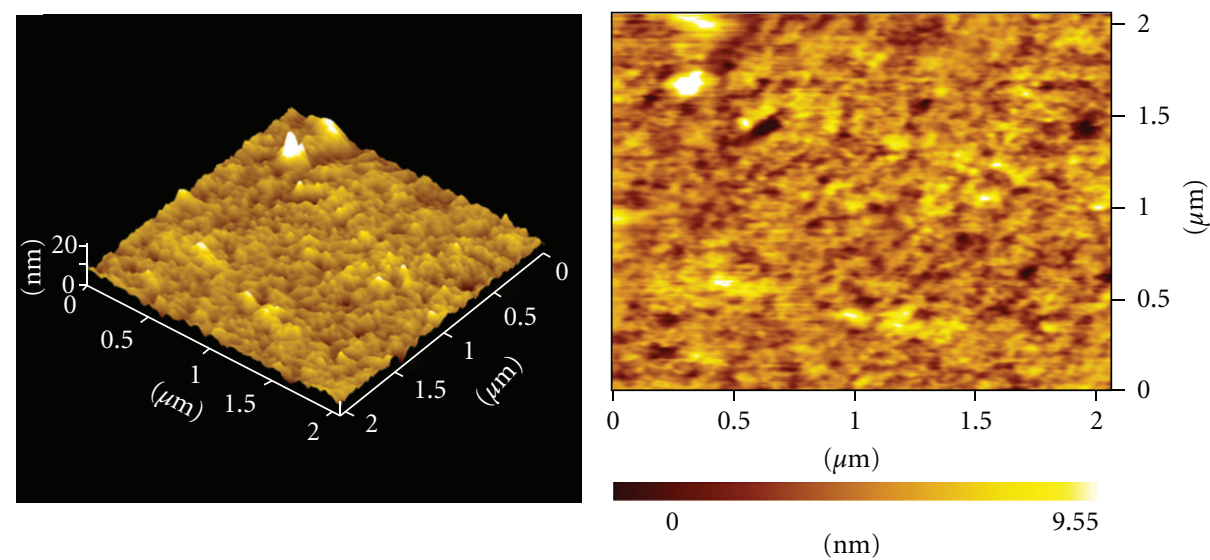

(a)
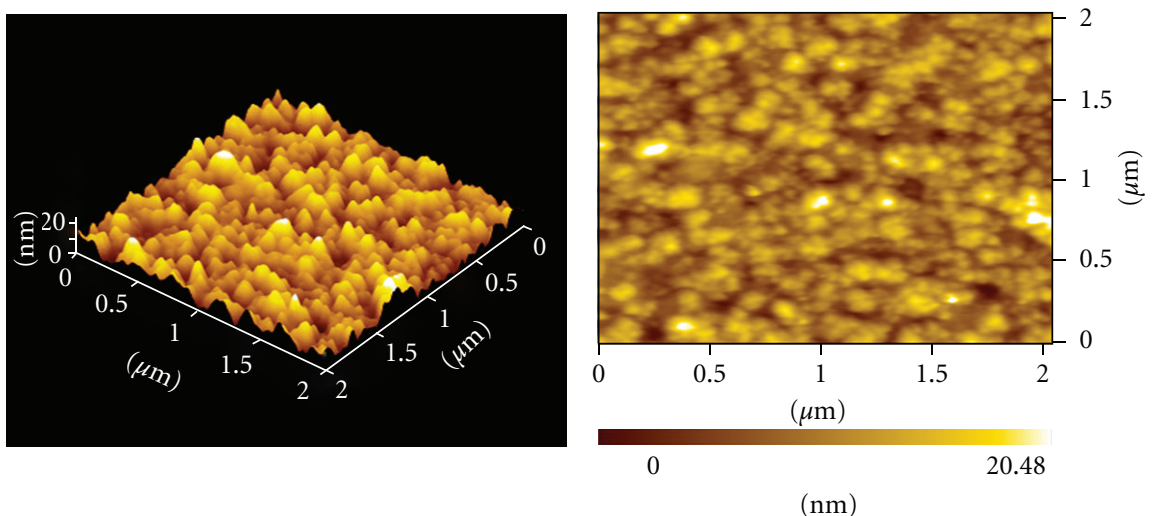

(b)
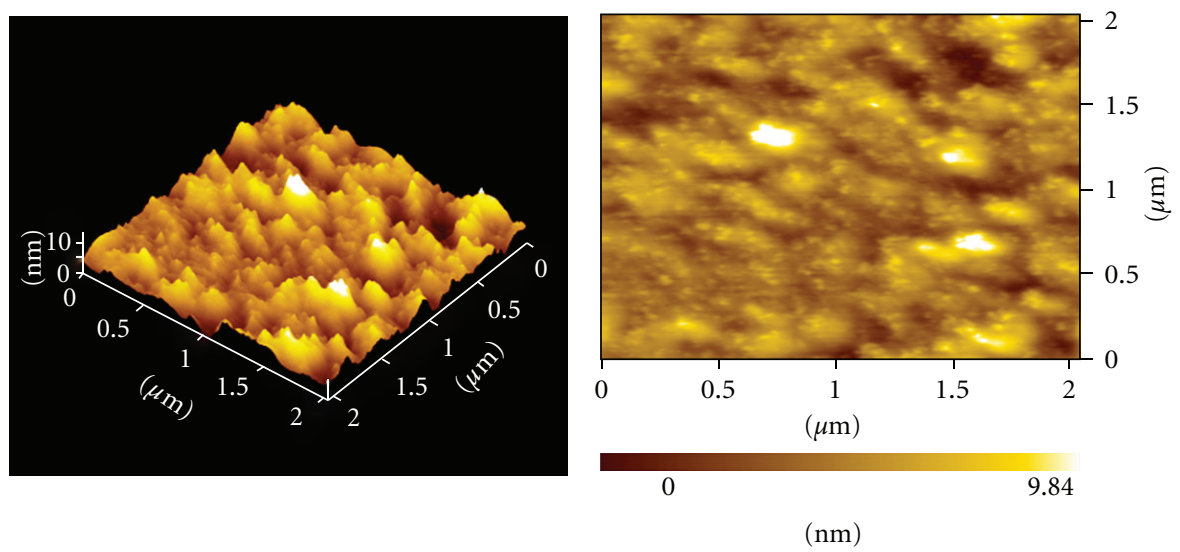

(c)

Figure 5: AFM images of $\mathrm{WO}_{3}$ films formed at oxygen partial pressures: (a) $4 \times 10^{-2} \mathrm{~Pa}$, (b) $6 \times 10^{-2} \mathrm{~Pa}$, and (c) $1 \times 10^{-1} \mathrm{~Pa}$.

with the increase of wavelength. At a wavelength of $550 \mathrm{~nm}$, the refractive index of the $\mathrm{WO}_{3}$ films decreased from 2.26 to 2.08 with the increase of oxygen partial pressure from $4 \times 10^{-2}$ to $1 \times 10^{-1} \mathrm{~Pa}$. The decrease in the refractive index at higher oxygen partial pressures was due to the decrease in the packing density of the films. In the literature, Mohamed et al. [16] reported that refractive indices at wavelength of $550 \mathrm{~nm}$ of the films decreased from 2.16 to 2.08 with the increase of oxygen partial pressure from
$2 \times 10^{-2}$ to $5.2 \times 10^{-2} \mathrm{~Pa}$ in $\mathrm{DC}$ magnetron sputtered $\mathrm{WO}_{3}$ films. Baloukas et al. [24] also observed the decrease in the refractive index from 2.21 to 1.97 with the increase of oxygen partial pressure from $1 \times 10^{-1}$ to $8 \times 10^{-1} \mathrm{~Pa}$ in the films formed by RF magnetron sputtering technique.

3.5. Photoluminescence. Figure 10 shows the photoluminescence spectra of $\mathrm{WO}_{3}$ films formed at oxygen partial pressures of $4 \times 10^{-2}$ and $6 \times 10^{-2} \mathrm{~Pa}$. The films deposited 


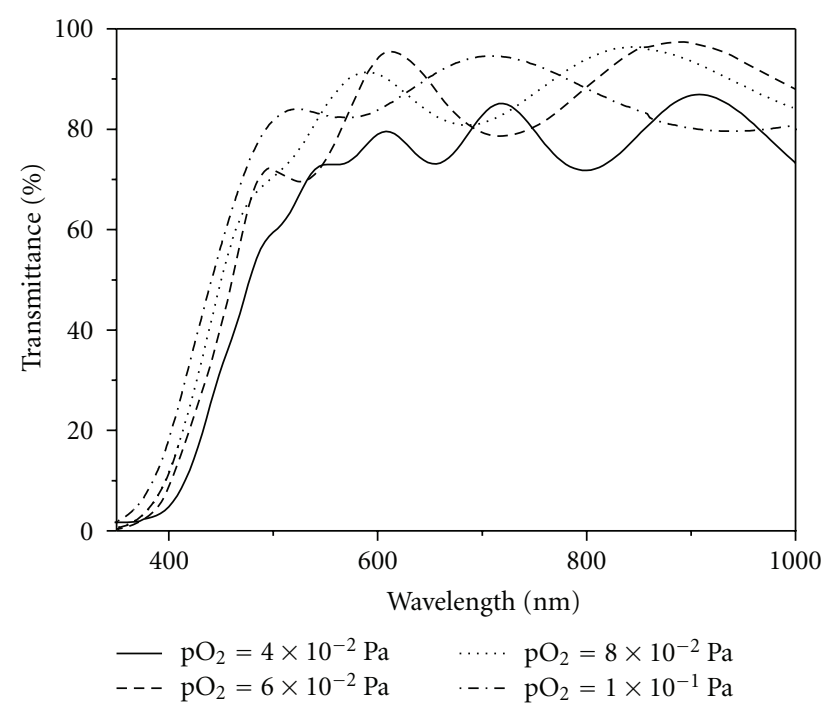

FIGURE 6: Wavelength dependence of optical transmittance of $\mathrm{WO}_{3}$ films.

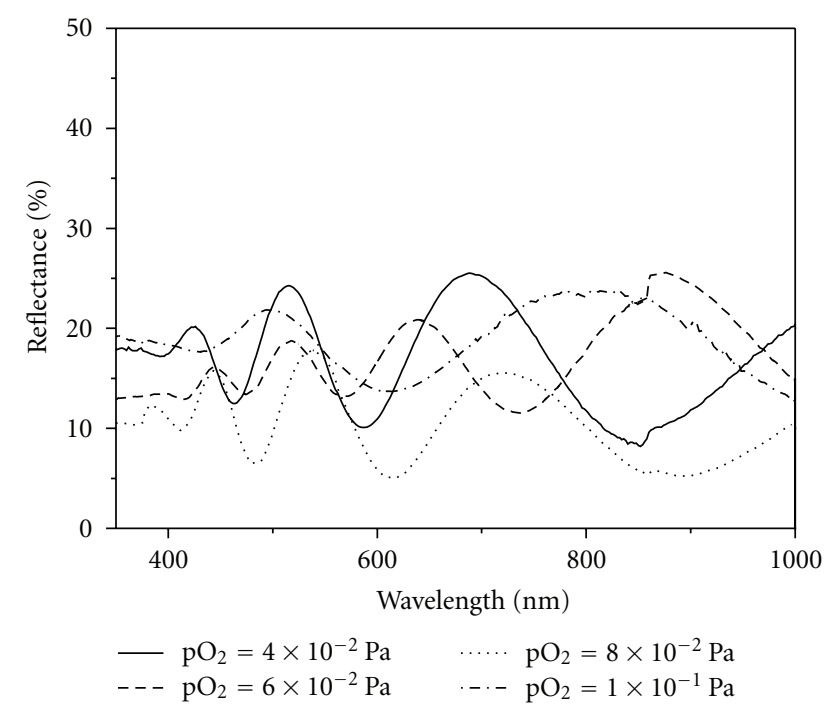

FIGURE 7: Wavelength dependence of reflectance spectra of $\mathrm{WO}_{3}$ films.

at low oxygen partial pressure of $4 \times 10^{-2} \mathrm{~Pa}$ exhibited two emission bands centered at about 410 and $440 \mathrm{~nm}$. The band seen at $410 \mathrm{~nm}$ was attributed to near ultraviolet emission. It was due to the presence of oxygen vacancies. Park et al. [25] reported that the occurred band was attributed to the localized state of oxygen vacancies in $\mathrm{WO}_{3-x}$ needle-like structure. A weak shoulder peak seen at $440 \mathrm{~nm}$ was the bluish green emission due to the presence of defects in the films. At oxygen partial pressure of $6 \times 10^{-2} \mathrm{~Pa}$, the peak shifted to $465 \mathrm{~nm}$ attributed to blue emission due to the reduction of oxygen vacancies. Niederberger et al. [26] and Luo et al. [27] suggested that the blue emission was attributed to the band-to-band transition. The possible reason that sufficient oxygen is available in the sputter chamber leads

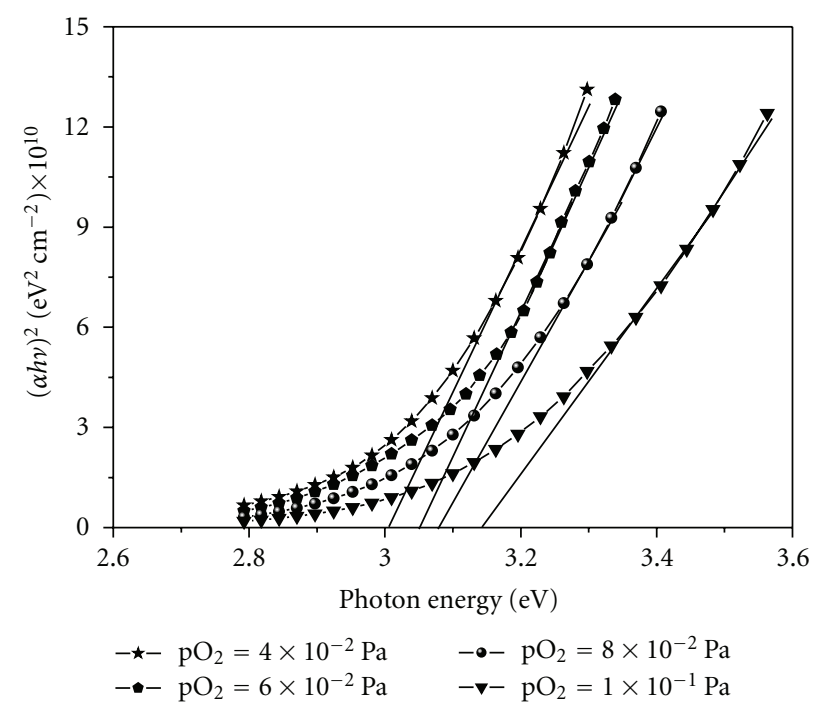

FIgURE 8: Plots of $(\alpha h \nu)^{2}$ versus photon energy $(h \nu)$ of $\mathrm{WO}_{3}$ films.

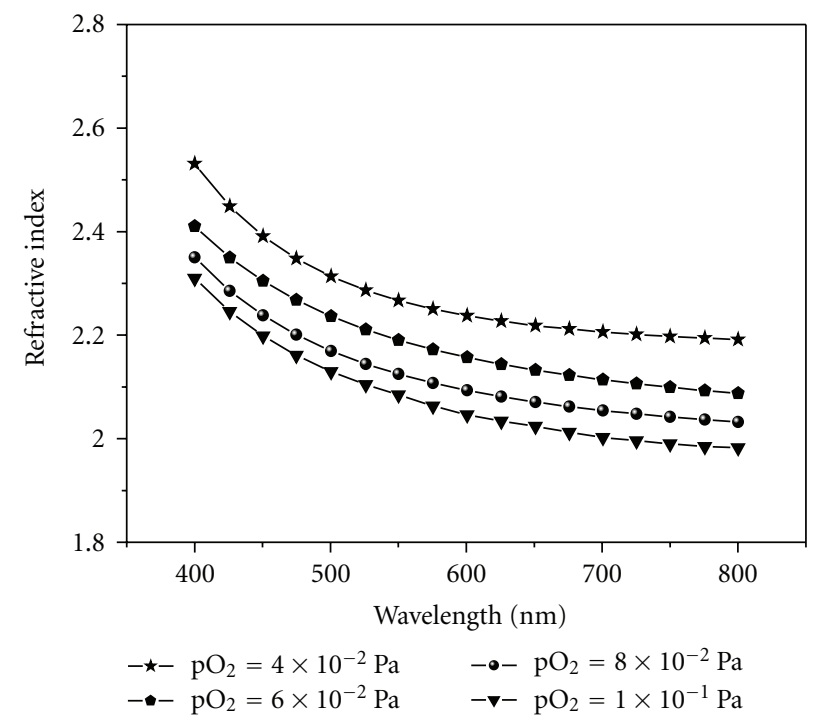

Figure 9: Variation of refractive index with wavelength of $\mathrm{WO}_{3}$ films.

to formation of stoichiometric $\mathrm{WO}_{3}$ films as explained in EDAX analysis and the films have $\mathrm{O} / \mathrm{W}$ ratio of 2.98 at oxygen partial pressure of $6 \times 10^{-2} \mathrm{~Pa}$.

\section{Conclusions}

$\mathrm{WO}_{3}$ thin films were deposited on Corning glass and silicon substrates held at room temperature by RF magnetron sputtering of tungsten target at different oxygen partial pressures in the range $4 \times 10^{-2}-1 \times 10^{-1} \mathrm{~Pa}$. The effect of oxygen partial pressure on the structure and surface morphology and the optical properties of the films were systematically investigated. The deposition rate of the films formed at low oxygen partial pressure of $4 \times 10^{-2} \mathrm{~Pa}$ was 


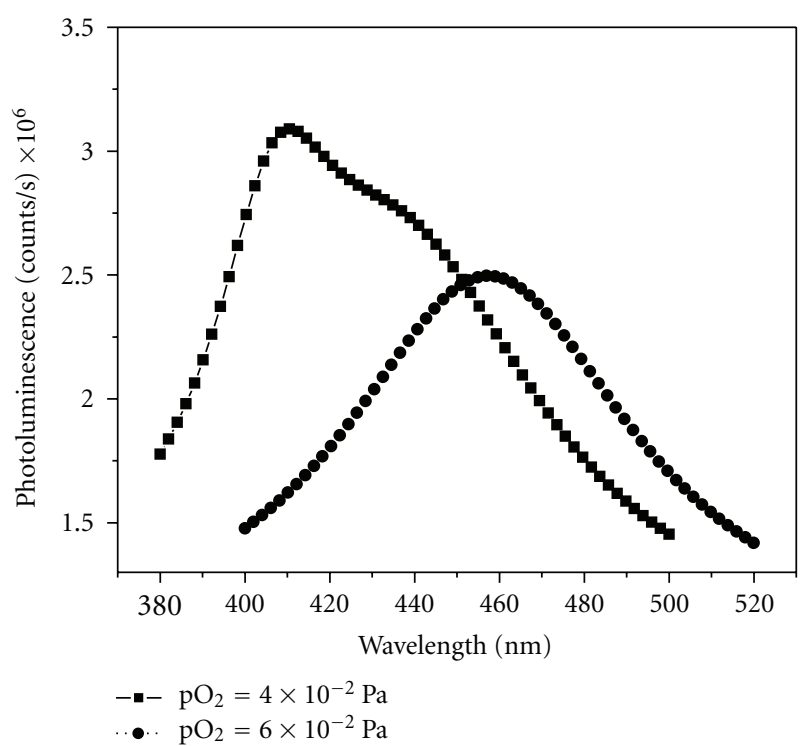

FIgURE 10: Photoluminescence spectra of $\mathrm{WO}_{3}$ films formed at oxygen partial pressures: (a) $4 \times 10^{-2} \mathrm{~Pa}$ and (b) $6 \times 10^{-2} \mathrm{~Pa}$.

$3.30 \mathrm{~nm} / \mathrm{min}$ and decreased to $2.62 \mathrm{~nm} / \mathrm{min}$ with increase of oxygen partial pressure to $1 \times 10^{-1} \mathrm{~Pa}$. EDAX analysis confirmed that the nearly stoichiometric films were obtained at an oxygen partial pressure of $6 \times 10^{-2} \mathrm{~Pa}$. X-ray diffraction studies revealed that the films were amorphous in nature. A broad hump in FTIR spectrum in the wavenumber range $500-1000 \mathrm{~cm}^{-1}$ was due to the stretching vibration of O$\mathrm{W}-\mathrm{O}$ observed in the films formed at higher oxygen partial pressures. The optical band gap of the films increased from 3.00 to $3.14 \mathrm{eV}$ and refractive index decreased from 2.26 to 2.08 with the increase of oxygen partial pressure from $4 \times$ $10^{-2}$ to $1 \times 10^{-1} \mathrm{~Pa}$, respectively. Blue emission was observed for the films deposited at an oxygen partial pressure of $6 \times$ $10^{-2} \mathrm{~Pa}$. The amorphous $\mathrm{WO}_{3}$ films formed at oxygen partial pressure of $6 \times 10^{-2} \mathrm{~Pa}$ with optical band gap of $3.06 \mathrm{eV}$ will be quite useful for electrochromic device applications.

\section{Acknowledgment}

One of the authors, V. Madhavi, is thankful to the University Grants Commission, New Delhi, India, for providing Junior Research Fellowship through sanctioned UGC-RFSMS during the course of the work.

\section{References}

[1] C. K. Wang, D. R. Sahu, S. C. Wang, C. K. Lin, and J. L. Huang, "Structural evolution and chemical bonds in electrochromic $\mathrm{WO}_{3}$ films during electrochemical cycles," Journal of Physics $D$, vol. 45, no. 22, Article ID 225303, 2012.

[2] F. Lin, C. P. Li, G. Chen et al., "Low-temperature ozone exposure technique to modulate the stoichiometry of $\mathrm{WO}_{x}$ nanorods and optimize the electrochromic performance," Nanotechnology, vol. 23, no. 25, Article ID 255601, 2012.

[3] O. M. Hussain, A. S. Swapnasmitha, J. John, and R. Pinto, "Structure and morphology of laser-ablated $\mathrm{WO}_{3}$ thin films," Applied Physics A, vol. 81, no. 6, pp. 1291-1297, 2005.
[4] A. Kaushal and D. Kaur, "Effect of oxygen partial pressure and $\mathrm{VO}_{2}$ content on hexagonal $\mathrm{WO}_{3}$ thin films synthesized by pulsed laser deposition technique," Journal of Nanoparticle Research, vol. 13, no. 6, pp. 2485-2496, 2011.

[5] C. Bittencourt, R. Landers, E. Llobet et al., "Effects of oxygen partial pressure and annealing temperature on the formation of sputtered tungsten oxide films," Journal of the Electrochemical Society, vol. 149, no. 3, pp. H81-H86, 2002.

[6] C. Bittencourt, R. Landers, E. Liobet, X. Correig, and J. Calderer, "The role of oxygen partial pressure and annealing temperature on the formation of $\mathrm{W}=\mathrm{O}$ bonds in thin $\mathrm{WO}_{3}$ films," Semiconductor Science and Technology, vol. 17, no. 6, p. $522,2002$.

[7] A. Subrahmanyam and A. Karuppasamy, "Optical and electrochromic properties of oxygen sputtered tungsten oxide $\left(\mathrm{WO}_{3}\right)$ thin films," Solar Energy Materials and Solar Cells, vol. 91, no. 4, pp. 266-274, 2007.

[8] H. S. Shim, J. W. Kim, Y. E. Sung, and W. B. Kim, "Electrochromic properties of tungsten oxide nanowires fabricated by electrospinning method," Solar Energy Materials and Solar Cells, vol. 93, no. 12, pp. 2062-2068, 2009.

[9] G. Leftheriotis, S. Papaefthimiou, and P. Yianoulis, "The effect of water on the electrochromic properties of $\mathrm{WO}_{3}$ films prepared by vacuum and chemical methods," Solar Energy Materials and Solar Cells, vol. 83, no. 1, pp. 115-124, 2004.

[10] W. L. Kwong, N. Sarvides, and C. C. Sorrel, "Electrodeposited nanostructured $\mathrm{WO}_{3}$ thin films for photoelectrochemical applications," Electrochimica Acta, vol. 75, pp. 371-380, 2012.

[11] K. Soon Ahn, S. H. Lee, A. C. Dillon, C. E. Tracy, and R. Pitts, "The effect of thermal annealing on photoelectrochemical responses of $\mathrm{WO}_{3}$ thin films," Journal of Applied Physics, vol. 101, no. 9, Article ID 093524, 4 pages, 2007.

[12] K. Hari Krishna, O. M. Hussain, and C. M. Julien, "Electrochromic properties of nanocrystalline $\mathrm{WO}_{3}$ thin films grown on flexible substrates by plasma-assisted evaporation technique," Applied Physics A, vol. 99, no. 4, pp. 921-929, 2010.

[13] H. Zheng, A. Z. Sadek, K. Latham, and K. Kalantar-Zadeh, "Nanoporous $\mathrm{WO}_{3}$ from anodized RF sputtered tungsten thin films," Electrochemistry Communications, vol. 11, no. 4, pp. 768-771, 2009.

[14] X. Sun, Z. Liu, and H. Cao, "Effects of film density on electrochromic tungsten oxide thin films deposited by reactive dc-pulsed magnetron sputtering," Journal of Alloys and Compounds, vol. 504, supplement 1, pp. S418-S421, 2010.

[15] Y. Li, S. Zhang, T. Sritharan, Y. Liu, and T. P. Chen, "Influence of oxygen partial pressure on magnetron sputtered $\mathrm{Sr}_{0.8} \mathrm{Nd}_{0.3} \mathrm{Bi}_{2.5} \mathrm{Ta}_{2} \mathrm{O}_{9+x}$ ferroelectric thin films," Journal of Alloys and Compounds, vol. 457, no. 1-2, pp. 549-554, 2008.

[16] S. H. Mohamed, H. A. Mohamed, and H. A. Abd El Ghani, "Development of structural and optical properties of $\mathrm{WO}_{x}$ films upon increasing oxygen partial pressure during reactive sputtering," Physica B, vol. 406, no. 4, pp. 831-835, 2011.

[17] T. A. Nguyen, S. Park, J. B. Kim et al., "Polycrystalline tungsten oxide nanofibers for gas-sensing applications," Sensors and Actuators B, vol. 160, no. 1, pp. 549-554, 2011.

[18] M. Deepa, M. Kar, and S. A. Agnihotry, "Electrodeposited tungsten oxide films: annealing effects on structure and electrochromic performance," Thin Solid Films, vol. 468, no. 1-2, pp. 32-42, 2004.

[19] A. Rougier, F. Portemer, A. Quede, and M. E. Marssi, "Characterization of pulsed laser deposited $\mathrm{WO}_{3}$ thin films for electrochromic devices," Applied Surface Science, vol. 153, no. 1, pp. 1-9, 1999. 
[20] M. Acosta, D. González, and I. Riech, "Optical properties of tungsten oxide thin films by non-reactive sputtering," Thin Solid Films, vol. 517, no. 18, pp. 5442-5445, 2009.

[21] K. J. Lethy, D. Beena, R. Vinod Kumar et al., "Nanostructured tungsten oxide thin films by the reactive pulsed laser deposition technique," Applied Physics A, vol. 91, no. 4, pp. 637-649, 2008.

[22] A. K. Chawla, S. Singhal, H. O. Gupta, and R. Chandra, "Effect of sputtering gas on structural and optical properties of nanocrystalline tungsten oxide films," Thin Solid Films, vol. 517, no. 3, pp. 1042-1046, 2008.

[23] R. Swanepoel, "Determination of the thickness and optical constants of amorphous silicon," Journal of Physics E, vol. 16, no. 12, p. 1214, 1983.

[24] B. Baloukas, J. M. Lamarre, and L. Martinu, "Electrochromic interference filters fabricated from dense and porous tungsten oxide films," Solar Energy Materials and Solar Cells, vol. 95, no. 3, pp. 807-815, 2011.

[25] S. Park, H. Kim, C. Jin, and C. Lee, "Intense ultraviolet emission from needle-like $\mathrm{WO}_{3}$ nanostructures synthesized by noncatalytic thermal evaporation," Nanoscale Research Letters, vol. 6, p. 451, 2011.

[26] M. Niederberger, M. H. Bartl, and G. D. Stucky, "Benzyl alcohol and transition metal chlorides as a versatile reaction system for the nonaqueous and low-temperature synthesis of crystalline nano-objects with controlled dimensionality," Journal of the American Chemical Society, vol. 124, no. 46, pp. 13642-13643, 2002.

[27] J. Y. Luo, F. L. Zhao, L. Gong et al., "Ultraviolet-visible emission from three-dimensional $\mathrm{WO}_{3-x}$ nanowire networks," Applied Physics Letters, vol. 91, no. 9, Article ID 093124, 3 pages, 2007. 

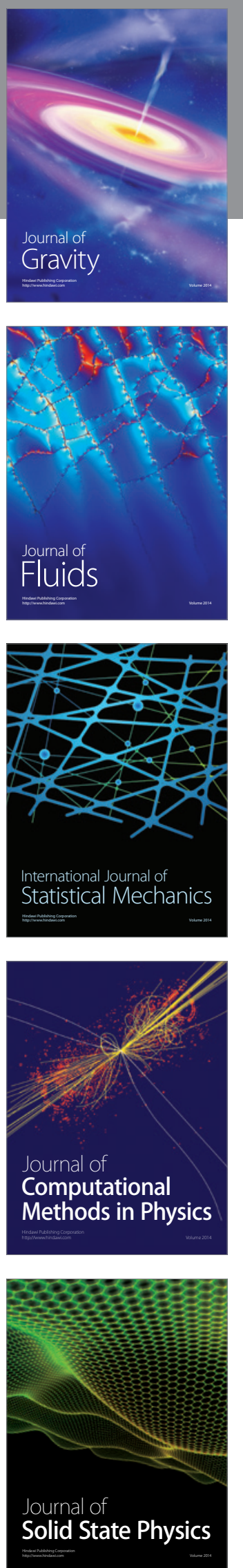
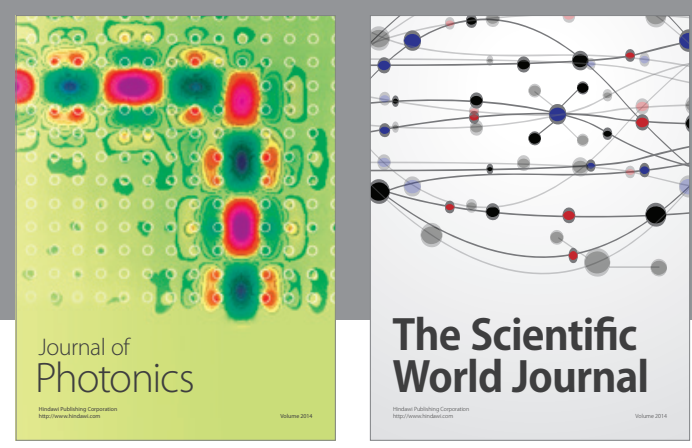

The Scientific World Journal

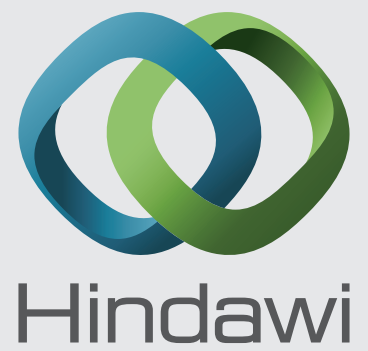

Submit your manuscripts at http://www.hindawi.com
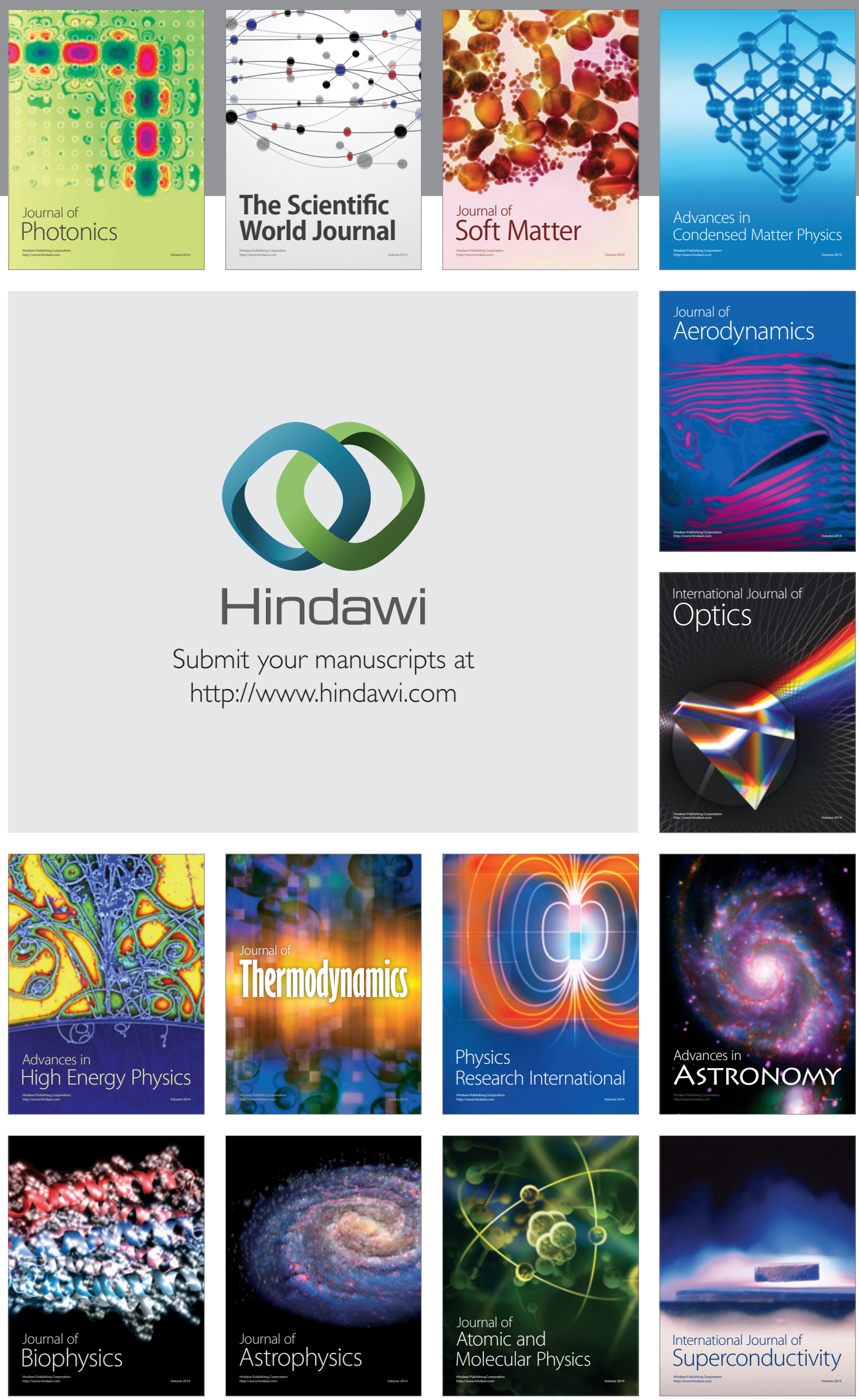
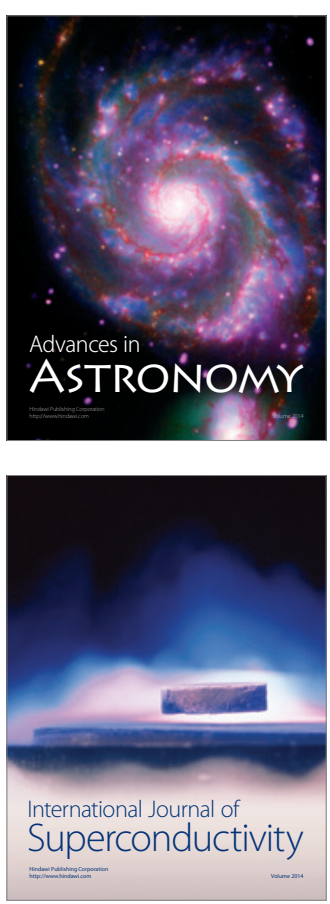